\title{
'Helping People Make Better Choices': exploring the behaviour change agenda for environmental sustainability
}

\section{Abstract}

This paper examines the emergence of market-orientated approaches to public participation in environmental issues through an exploration of recent empirical research into 'sustainable lifestyles' as a practical tool for encouraging proenvironmental behaviour. Using the notion of 'sustainable lifestyles', current social marketing policies seek to encourage behaviour change amongst citizens by identifying population segments with similar commitments to environmental practices as the basis for behaviour-change initiatives. However, the use of static 'lifestyle groups' implies that that citizens replicate sustainable practices across different consumption contexts and this paper explores this line of argument through the use of data collected as part of a recent UK Department for the Environment, Food and Rural Affairs (DEFRA) funded research project on sustainable lifestyles and climate change. Through a series of focus group discussions, participants explored notions of sustainable practices using the home and leisure contexts as framing devices to explore issues of environmental responsibility and climate change. The emphasis placed on practices and context reveal that the comfortable notions of environmental responsibility and sustainable consumption in the home are often in conflict with the discourses of consumption reduction associated with climate change in leisure and tourism contexts. In many cases, these 'paradoxes' are explicitly referred to, reflectedupon and discussed by participants who demonstrate that notions of sustainable practice are mediated by practice and spaces of consumption. Accordingly, the 
paper argues that in conceptualising market-based approaches to behaviour change around the notion of 'sustainable lifestyles', researchers and policy makers need to address the role of context and recognise the importance of consumption spaces and the conflicts that may arise between these.

Key words: Sustainable lifestyles, behaviour change, climate change, social marketing. 


\section{INTRODUCTION}

Of the many issues surrounding global environmental change currently being explored, that of how to encourage and sustain appropriate levels of individual behavioural change is amongst the most pressing for policy makers (DEFRA, 2005; 2008). Even a brief glance at successive UK sustainable development strategies since 1994 reveals a shifting emphasis in the scales at which national governments believe sustainable development can be promoted (Moffatt, 1996; Connelly and Smith, 2003; Barr, 2008). Indeed, as the scale of environmental challenges has become increasingly globalised, there has been a progressive shift towards governing environmental issues at local and regional scales and, most recently, an emphasis on individuals as agents for change (DEFRA, 2008).

This re-scaling of responses to environmental challenges towards a focus on 'the individual' has resulted in a policy imperative to encourage a major shift from passive to active publics in the context of global environmental concerns (Owens, 2000). One particular strand of research emphasises the need to utilize 'social marketing' to promote behaviour change. Such an approach seeks to use conventional marketing techniques as a means of promoting behavioural change for a 'social good', through identifying target behaviours for change, audience segmentation and marketing messages (French et al., 2009). Accordingly, social marketing places emphasis on incremental, practical and achievable changes to practices relevant to a specific target audience.

This paper uses data gathered from a research project undertaken for the Department of the Environment, Food and Rural Affairs (DEFRA) that explored the role of social marketing approaches for promoting 'sustainable lifestyles' amongst residents of Exeter in the UK. The research explored the ways in which 
using audience segmentation (the main basis for a social marketing campaign) reflected the discourses that emerged when discussing existing and 'conventional' forms of environmental behaviours (such as energy and water use, recycling and transport use in daily life) when compared to more radical options for behavioural change that have emerged with the growing public awareness of global climate change (such as reductions in personal carbon emissions by flying less frequently for leisure). These more 'radical' options potentially challenge the comfortable relationship between individuals and consumption and may do so in particular contexts (such as the leisure and tourism context, versus the home environment) where behaviours are practiced within different cultural, economic and social settings. Indeed, to Crompton and Thogersen (2009) it is the tension between 'comfortable' forms of proenvironmental behaviour and radical changes to lifestyles and consumption patterns that has led them to argue against the predominant consumerist ideology as the basis for behavioural change strategies:

"The comfortable perception that global environmental challenges can be met through marginal lifestyle changes no longer bears scrutiny. The cumulative impact of large numbers of individuals making marginal improvements in their environmental impact will be a marginal collective improvement in environmental impact. Yet we live at a time when we need urgent and ambitious changes" (Compton and Thogersen, 2009, p. 6).

The aim of the research reported in this paper was therefore to understand the utility of adopting social marketing approaches across a range of pro-environmental behaviours and contexts in order to highlight both the 
opportunities and potential challenges of using 'social marketing' as the major mechanism for behavioural change. The paper starts with an exploration of social marketing approaches towards behaviour change in an environmental context, demonstrating the ways in which this technique is being used in a practical policy context to frame 'sustainable lifestyles' as a means of promoting behavioural change. The paper then outlines the basis for the empirical data used in the research, which were collected as part of a research project on sustainable lifestyles for the UK's Department for the Environment, Food and Rural Affairs (DEFRA). Through an exploration of qualitative data generated from focus group discussions, the paper examines how individuals in different 'lifestyle groups' frame environmental action and the ways in which attitudes and commitments towards the environment are mediated by the issue of climate change. The paper concludes by exploring the potential for social marketing and the use of 'sustainable lifestyles' as a way to promote behavioural change in different contexts and the role of climate change in framing attitudes towards environmental actions in these contexts.

\section{THE 'SOCIAL MARKETING' OF 'SUSTAINABLE LIFESTYLES'}

The arguments of Crompton and Thogersen (2009) hint at the tension emerging between advocates of incremental and consumer-focused changes in proenvironmental behaviour with those who argue for radical and often unspecified changes in society to combat issues such as global climate change. However, as Clarke et al. (2007) have noted, the importance of individuals as consumers who must exercise 'choice' in the market place as 'good' citizens is firmly placed at the centre of existing UK Government policies aimed at tackling environmental 
issues, recently reinforced by the Government's announcement on the 'Big Society' in which the Government aims to:

“...give citizens, communities and local government the power and information they need to come together, solve the problems they face and build the Britain they want.” (Cabinet Office, 2010, p. 1)

Indeed, it is unlikely that current political and economic conditions in most western democracies favour anything but the current Neo-liberal approach towards social and environmental policy making, which has sought to roll back the state's role to place the responsibility for many social and environmental issues on 'citizen-consumers' (Clarke et al., 2007; Scammell, 2000; Spaargaren, 2004). In the words of the British Prime Minister:

"You can call it liberalism. You can call it empowerment. You can call it freedom. You can call it responsibility. I call it the Big Society." (Prime Minister's Office, 2010)

Accordingly, in the light of this political context, it is worth exploring the basis for current policy on behavioural change, using the UK as a case example. As we might expect, consumer choice and pro-activity is central to this debate and in a chapter entitled 'Helping People Make Better Choices' the UK government makes the case for behaviour change (DEFRA, 2005, p. 25):

"We all - governments, businesses, families and communities, the public sector, voluntary and community organisations - need to make different choices if we are to achieve the vision of sustainable development".

The practical implementation of this policy goal has been secured through considerable investment by the UK's Department for the Environment, Food and Rural Affairs (DEFRA) in developing the UK's Framework for 
Environmental Behaviours (DEFRA, 2008), which has embraced the notion of citizen-consumers through adopting a social marketing approach to 'sustainable lifestyles'. In applying a fundamentally market-based concept to behaviour change, there is an implicit assumption that behaviour changes are only likely to emerge within existing and dominant discourses of consumption and that using techniques which have proved successful in changing other consumption habits (such as smoking reduction) may also be effective in promoting changes in environmentally-related consumption (Frame and Newton, 2007; French et al., 2009; McKenzie-Mohr and Smith, 1999; NSMC, 2008). As a concept, social marketing:

“...underscores the importance of strategically delivering programs so that they target specific segments of the public and overcome the barriers to this segment's engaging in the behavior" (McKenzie-Mohr, 2000, p. 594).

According to Andreasen (2006), social marketing applies these ideas within conventional marketing frameworks, relying on concepts such as consumer peer pressure, benefits and costs of adopting the behaviour and the importance of self-identity. However, it is the focus on segmentation that characterises environmental approaches towards behaviour change and in applying social marketing techniques both DEFRA and a range of other agencies (Darnton and Sharp, 2006) have relied on segmentation as the basis of their strategies. Segmentation therefore becomes the framing device for the social marketing of what are, in marketing terms, 'sustainable lifestyles'.

The notion of 'sustainable lifestyles' has, and continues to be a somewhat slippery and ill-defined concept, used in a variety of disciplinary and 
political contexts and it is beyond the scope of this paper to discuss the range of contexts in which the term has been applied (Jackson, 2005). However, the upsurge in social marketing approaches towards behaviour change has cemented one particular definition of the term as being framed by a set of behaviours and / or attitudinal characteristics towards a range of pro-environmental behaviours (such as recycling waste, saving water and energy, 'green' or ethical consumption, travel and conservation) that characterise a particular population segment. Darnton and Sharp (2006) noted that at least 25 different segmentation (or 'lifestyles') models existed within the literature at the time of writing which have mainly been applied at the interface between academic and policy research (Anable, 2005; Barr and Gilg, 2006; Dallen; 2007).

However, the emphasis on social marketing and the use of sustainable lifestyles as a framing device by both academics and practitioners has not been without criticisms. Building on the essential arguments of Johnson (2008), Peattie and Peattie (2009, p.261) critique the fundamental basis for using social marketing in the promotion of sustainability, arguing that:

"Creating meaningful progress towards sustainability requires more radical solutions than just the development of new products and product substitutions amongst consumers...The anti-consumption challenge poses some critical questions about how to promote such concepts to make them acceptable to consumers, and what role the discipline of marketing can and should play in this process".

Indeed, aligned with the broader critiques of citizen-consumer logics, Peattie and Crane (2005) and Peattie and Peattie (2009) argue that the promotion of consumption reduction is highly problematic for social marketing 
practitioners and thus results in relatively unambitious and small-scale attempts to change behaviours (Crompton and Thogersen, 2009). However, there are also specific criticisms which can be levelled at the segmentation-based sustainable lifestyles approach that is one of the main elements of social marketing, irrespective of the wider debates concerning the 'power' of citizen-consumer to effect the 'right' levels of behaviour change.

In applying segmentation techniques to a wide range of behavioural goals (from reductions in short-haul air travel to recycling paper and aluminium cans), social marketers can be open to the accusation of viewing sustainable lifestyles as relatively unproblematic and discrete sets of practices in people's lives. Yet there is evidence that some inconsistency emerges between different forms of environmental practice according to the context in which they are undertaken. A useful example is provided by CACI (2009) of the geographically defined household data on pro-environmental behaviours in the UK. For example, those living in some of the 'greenest' areas (as defined by activities such as recycling, energy conservation and green purchasing) also tended to have the highest carbon emissions, accounted for by ownership of more or larger vehicles and a tendency to fly further and more frequently for holidays.

Such evidence points to an inconsistency that may be present within existing definitions of sustainable lifestyles and potentially raises questions concerning the ability of practitioners to promote such 'lifestyles' rather than isolated behaviours. From a policy perspective, the reality of this proposition would be that if the 'home' continues to be used as the main framing device for studying and promoting sustainable practices, there may be only a limited impact on tackling wider issues of climate change, which is influenced by 
carbon emissions that arise not only from home energy use but also from travel, particularly private car use and air travel. Accordingly, to understand and appreciate these issues, a focus away from the home and towards sites of practice that incorporate travel and issues of climate change is needed to adequately deal with the notion of sustainable lifestyles.

The theoretical and political shift towards a market-orientated perspective has therefore resulted in a distinct intellectual and practical approach towards promoting behaviour change, one that is grounded in using marketfacing mechanisms (such as social marketing) to promote sustainable lifestyles. It is the contention of this paper that whilst this approach may be adequate for adjusting consumer practices within and around the home context, the citizenconsumer perspective (and by definition sustainable lifestyles) has largely neglected sites of practice that represent forms of consumption and in which citizen-consumer logics may become challenged. This partly arises because of the existing empirical focus of research in this field. First, there is a tendency to focus on particular behaviours or practices, such as conserving energy, saving water or recycling waste. Second, research is mostly undertaken within the home context, focusing on the everyday and routinised practises of individuals. We argue that the these two issues mask significant theoretical and practical problems for applying the notion of 'sustainable lifestyles' across different context and that current political imperatives for using such a construct through social marketing methodologies is likely to be ineffective when these are applied outside the narrow confines of the home context and relate to contested issues such as climate change. 
In developing these lines of argument, the paper will use data gathered from a research project entitled Promoting Sustainable Lifestyles: a social marketing approach commissioned by the UK Department for the Environment, Food and Rural Affairs (DEFRA), which aimed to examine the potential for using social marketing methodologies to promote behaviour change amongst a series of lifestyle groups identified from previous research based in South West England funded by the Economic and Social Research Council of the UK (ESRC) (Barr and Gilg, 2006). These lifestyle groups had been derived from a quantitative cluster analysis of 36 reported behaviour items from 1265 questionnaire respondents covering energy and water saving, recycling and 'green' forms of consumption. Four lifestyle groups were identified, respectively classified as 'Committed', 'Mainstream', 'Occasional' and 'non-environmentalists' (Barr and Gilg 2006).

The data for this paper comprise focus group transcripts of meetings held with individuals in 2006 in the South West of England. The choice of this study location was based on the need to link the data collection with that used for the previous ESRC study. The South West of England, with a population of 5.2 million (National Statistics, 2010) is one of the largest English regions and represents a wide range of socio-economic contexts, from sparsely populated rural areas, through market towns and small cities, to several large postindustrial cities (e.g. Bristol and Plymouth). Accordingly, although the region evidently has specific social and economic conditions, it contains many diverse characteristics that make it a useful case study of the English population. 
Individuals for the focus groups were selected according to their responses to recruitment surveys that collected a variety of quantitative and contextual data. Within this survey a series of questions asked respondents how often they engaged in a range of pro-environmental behaviours in and around the home that aligned to those measured in the previous ESRC research. Indeed, for the purposes of examining the effectiveness of segmentation as an approach to promoting sustainable lifestyles, the project aimed to base its design on a social marketing methodology. Through examining responses to behavioural items in the recruitment survey, individuals were nominally assigned to a focus group with individuals displaying similar behavioural characteristics to one of the four groups identified by the ESRC research. Two focus groups were held with individuals representative of each cluster (eight groups involving 57 individuals in total). All group discussions were semi-structured and the moderator asked a wide ranging set of questions related to pro-environmental behaviour, sustainability, travel, tourism and climate change. Appendix 1 provides the demographic profile of the focus group participants.

The remainder of the paper presents three arguments to clarify and develop the notion of 'sustainable lifestyles' by focusing on discourses of environmental practice in the 'home' context (where we argue that the citizenconsumer construct is an effective concept), the issue of global climate change (where we argue that environmental conflicts emerge between conventional and new pro-environmental practices) and the 'leisure' context (where this alternative site of practice presents a challenge to the dominant logic of the 'sustainable lifestyle' concept). 


\subsection{Embedded Sustainability 'in and around the home'}

The dominant site of practice in which the 'sustainable lifestyle' has been studied and promoted is within the home context, focusing on a range of sustainable behaviours that relate to daily and weekly practices of consumption. It is at this scale and within this context that the citizen-consumer construct and the aligned social marketing strategies have arguably achieved the most success because calls to change lifestyles to incorporate environmental concerns are closely related to existing, everyday practices (Shove, 2003).

The participants in the focus groups were, irrespective of segment, largely in agreement that pro-environmental actions in and around the home were positive and posed little threat to accepted social norms:

"I think it's something you get into a routine with isn't it?" (5A, Occasional)

"Well it's fairly easy like by turning lights off and things, and the little red light on the T.V”. (5A, Occasional)

"Yeah it's fairly easy now they've got green bins that they provide for recycling" (5C, Occasional)

Evidently the acceptance of pro-environmental practice as largely desirable and 'normal' forms of behaviour did not mean that everyone participated; indeed, the basis for the segmentation of the groups was predicated on different levels of commitment to a range of environmental practices. However, the barriers that individuals perceived when discussing their behaviours were practical in nature:

"Yep. I think it is a good thing, but going back I think it is a bit of an inconvenience because you're always thinking about what you're 
chucking away and a lot of things have to be washed or rinsed before you put them in so it is an inconvenience isn't it?" (3C, Mainstream)

These notions of inconvenience were embedded within a discourse that was accepting, amongst all groups, of the basis for environmental behaviours. Accordingly, when discussing different forms of environmental practice, individuals were able to do this at ease and were able to reflect on their own behaviour:

"I mean I know I waste water by brushing my teeth and leaving the tap running but I just don't get around to do something about it all the time”. (3C, Mainstream)

Within this context, the framing of home-based environmental actions by all groups was around the issue of self-efficacy and the pragmatic issues of space and time, as this discussion of home composting illustrates:

"When you've only got a small garden you got nowhere to put it". (5A, Occasional)

"I'm the same. I'd love to do it but I don't have anywhere to put it. No space”. (5E, Occasional)

"I live in a flat now and if there was a communal compost heap where you could put your waste and use to fill your pots, that'd be nice". (5D, Occasional)

"I don't think it is that difficult if you've got the space. It just takes a little bit of separating things out". (5B, Occasional)

"There is a compost heap but it was kind of abandoned ages ago and now its just there not being used. I just don't get around to it. I feed all the scraps to the birds and that's it really". (5C, Occasional) 
These discourses suggest that messages of 'Small Change' (Crompton and Thogersen, 2009) are penetrating a wide range of discourses. These relatively minor changes in lifestyle cover minor adaptations to consumer purchasing, resource use and management of the waste stream. Indeed, there was little evidence that individuals in the focus groups sought to challenge the basis for the consumer society on which their current habits were formed. Accordingly, 'home' based behaviours represented a relatively convenient and simple way of making minor lifestyle changes that had few or no consequences for overconsumption practices. In this way, such practices became accepted as normal behaviour; the reasons for non-participation being pragmatic and largely unprincipled in nature.

Such findings corroborate the research led by scholars advocating a social practices approach (Spaargaren, 2004; Shove, 2003; Shove et al., 2007), who have argued that the interpretation of 'environmental' practice needs to be placed within the wider context of normal, everyday habits that illustrate the underlying demands consumers make on resources. Using this approach, the meshing of social and environmental practice becomes an unproblematic issue within the home context, because established levels of consumption remain unchallenged and there is only a minor call to adjust existing practices. Accordingly, differences between lifestyle groups are largely pragmatic and not fundamentally driven by underlying values, beliefs or ethics. As such, the home context provides the perfect site of practice to advocate and cultivate the citizenconsumer; as a site of practice that does not create conflict between the collective responsibility of environmental protection and the self-interest and identity value of consumption. 


\subsection{The 'Sustainable Lifestyle' in a Changing Climate}

If the home context provides the natural place for the 'sustainable lifestyle', the related issues of climate change and travel and tourism may represent subjects and sites of conflict and challenge for this construct. There is evidence to support drawing some distinction between home-based environmental practices and the issue of climate change; needless to say in scientific terms practices at home are critical in framing climate futures, yet evidence suggests that the subject of climate change is largely separated in individual and collective consciousnesses from 'localised' environmental practice (Lorenzoni et al., 2007). This separation of consciousness is potentially highly problematic for the scientific and policy community as they attempt to promote behaviour change amongst lay publics and has major implications for social marketing concepts applied across different behavioural contexts. In this and the following section, we aim to illustrate how the issue of climate change and its discursive treatment by tourists demonstrates a challenge to the social marketing agenda through both the contestation of climate change as an issue and the ways in which seemingly 'committed' environmentalists regard behaviour whilst on holiday or 'at play'.

The discourses associated with climate change have been well documented by a succession of studies (Poortinga and Pidgeon, 2004; Lorenzoni and Pidgeon, 2006; Stoll-Kleeman et al., 2001). However, these studies have largely been undertaken independently of research on existing, home-based environmental practices and have remained separate from notions of sustainable lifestyles. Yet to evaluate the efficacy of the lifestyles approach it becomes imperative to contrast existing levels of environmental behaviours to wider 
attitudes towards climate change, a key government priority. Accordingly, in the focus groups, individuals were asked whether they were concerned about, and felt responsible for, global climate change. Amongst those least committed to environmental behaviours, the following discourses emerged:

"I'm not sure that pollution from man is that great because you see reports on the news of this volcano that's erupting and how much pollution it's putting into the air and it outweighs us by quite a large amount. So you come to think is it really that bad. I'd say we only do about $2-3 \%$ of it." (7G, Non-environmentalist)

"Basically you're looking at Tsunamis happening and the raise in temperatures... It's supposed to be coldest in Britain at this time so it's all related" (8F, Non-environmentalist)

Both of these quotations illustrate the challenges that have emerged in recent years regarding climate change: perceptions of scientific uncertainly, conflation of global events to equate with climate change and a conclusion that 'man' is not responsible for global warming (Lorenzoni et al., 2007). However, in discussing climate change with more committed individuals, a surprising set of discourses also emerged:

"I'm yet to be convinced that it is man that's responsible for global warming. There are known blips in the world's weather. Many ice ages, many heat waves and I believe that this is probably another blip". (2G, Committed)

"I don't [think] that it's anything to do with our lifestyle that we'll see a change within our lifetime". (3E, Mainstream) 
Whilst other members of the Committed and Mainstream groups were a little more equivocal concerning the causes of climate change, only a couple of individuals seemed to assign responsibility firmly with humankind. Persistent discourses included: 'humankind can't have that big an effect'; 'the world changes anyway' and 'it won't happen in my lifetime'. Accordingly, those generally committed to a range of home-based environmental behaviours were mostly willing to accept that the climate was changing, but this was unrelated to human behaviour and particularly their own activities.

These findings have significant implications for both the perception and promotion of climate change mitigation; we found only limited evidence to suggest that even those most committed to a whole range of environmental behaviours in and around the home were more than a little concerned with human induced climate change. This suggests that climate change does represent a separate consciousness for the citizen-consumer and one that can be detached from the everyday practice of being environmentally friendly.

An analysis of the focus groups reveals a common set of discourses that reinforce this separate consciousness throughout the segments:

“That's all well and good but when I see the council diesel lorries coming round to collect our recycling two or three times a week, it makes me think that they're not doing much good for the environment either". (2A, Committed)

"We might buy their [industry's] products but it's the people in the industry who should be taking measures to be more environmentally friendly". (6C, Occasional) 
"But it is discouraging when you hear on it that places like America won't sign up to the Kyoto agreement or whatever you call it. That's just pushing us into thinking 'well, why should we bother?' because such a large country like that and they're just not even acknowledging that global warming is happening!" (6A, Occasional)

Overall, few in the groups were willing to assign responsibility for climate change to themselves or individuals as a whole. Rather, discourses of climate change were imbued with external notions of accountability, placed various at the feet of governments, industry and even other nation states. What Stoll-Kleeman et al. (2001) regard as strategies for climate change 'denial' were clearly evident in all of the groups and once again illustrated the separate consciousness climate change as an issue has from the everyday practice of environmental behaviour.

In demonstrating the fundamental differences in the lifestyle groups between the acceptance and practice of environmental behaviours in the home and the issue of climate change, there is evidently a challenge that needs to be addressed by proponents of social marketing. Even individuals with high commitments to the environment were largely unwilling to ascribe climate change as a phenomenon caused by humans and for which they were personally responsible (Leiserowitz, 2005). This is a sufficient challenge in itself, but the potential underlying implication of this finding is also significant: that climate change represents a separation of consciousness not only because of the many reasons cited by other scholars (Lorenzoni et al., 2007; Whitmarsh, in press), but also because it challenges the basis for consumption on which contemporary 
neo-liberal society is built, the 'comfort zone' with which few are willing to contemplate disturbing:

"Ultimately, there is a need for UK policies and governance structures to initiate a systemic shift to a low consumption paradigm in order to move people out of their comfort zone of carbon-intensive living" (Lorenzoni et al., 2007, p. 456)

\subsection{Sustainable Tourists: a paradox?}

By way of illustrating the ways in which climate change poses a challenge to the happy consensus between environmental responsibility and continuing levels of consumption in the home, the case of tourism will be examined as an example of exploring the role of the citizens outside of the 'everyday' (or 'daily') - in extraordinary and liminal sites of practice. In so doing, we will make specific reference to the recent media debates that have emerged concerning the impact of flying on climate change. As noted by Becken and Hay (2007) tourism's impact on the climate has recently come under the spotlight as the importance of travel has emerged as a contributor to climate change emissions (Chapman, 2007; Stern Review, 2006). Tourism itself can be a carbon-intensive activity both in terms of the travel, and behaviour within, a resort destination. Indeed, subsequent research by the authors (Barr et al., 2010) has explored the wider role of sustainable tourism practices at the destination and their relationship to similar practices in the home context. However, in recent years it is the act of travelling to and from destinations that has gained most attention from researchers, largely because of the carbon-intensive nature of some forms of transport, especially air travel (Graham and Shaw, 2008; Gossling and Peeters, 
2007; Hunter and Shaw, 2007). Indeed, the significant growth in low cost carriers (LCC's) has generated considerable media interest in both the access to and affordability of short-haul, European breaks from the UK (Graham and Shaw, 2008; Ryley and Davison, 2008). Accordingly, the research in this paper sought to explore the ways in which individuals responded to popular debates concerning climate change and flying in this specific national and continental context.

By way of exploring the issue of climate change within a different site of practice, individuals within the focus groups were asked to discuss the ways they helped the environment whilst on holiday and in particular their attitudes towards flying and climate change. For those individuals least committed to the environment in the home, the discussion of flying and climate change was brief:

"I don't really think about it to be honest". (8A, Non-environmentalist)

However, individuals in these groups were pro-active in describing the various benefits the expansion of low cost carriers had brought them:

"...these low cost airlines connect the areas which are not connected or reached by the bigger airlines" (8F, Non-environmentalist)

"You can go to places that you can't with the bigger airlines" (8E, Nonenvironmentalist)

Benefits were also highlighted by individuals within the other lifestyle segments and for many in the Occasional groups, the decision to fly for domestic travel was an obvious one:

"And like, my eldest daughter lives in Darlington and I can go with FlyBe for $£ 60$ to Newcastle and it takes one hour or I can go on a coach 
for eleven hours or train for six hours and that's more expensive, so that's the choice I make" (6B, Occasional)

Accordingly, for individuals with limited environmental commitments in and around the home, flying was not seen as problematic in an environmental context; conversely, flying had brought significant benefits and the opportunity for enhanced, cheap and fast travel. This lack of connection between flying and climate change is not surprising given the preceding analyses of individuals within these lifestyle groups. However, for those with more commitments towards the environment in and around the home, the issue of climate change and flying raised more contested and complex discourses. When asked whether they flew by low cost carriers, most individuals in the committed and mainstream groups reported that they had done so and there was some heated discussions on the role of flying and climate change:

"Which is more efficient a plane half full with executives flying abroad for a conference or a low cost airline, full to the brim with people going on holiday?" (4F, Mainstream)

"I suppose if it wasn't for cheap airlines, I wouldn't be going snowboarding this year" (4E, Mainstream)

"Yeah and if it wasn't for cheap flights, I wouldn't have seen half of the wonderful places that I've been to, which in turn makes you think about the environment more" (4A, Mainstream)

These extracts illustrates the tensions that emerge from a discussion of climate change, flying and person responsibility. The second and third quotations make specific reference to the contradiction that is implicit between calls to reduce flying for the sake of climate change and the implications this 
would have for symbolically important leisure consumption practices of individuals. Accordingly, within those groups who held strong home-based environmental commitments, a conflict had emerged between their proenvironmental lifestyle and the demands of consumption, a conflict manifested in a heavily commodified site of practice associated with hedonism and getting away from the 'everyday'. To this extent, even the most committed environmentalists considered a change in these forms of consumption a major challenge:

“...you can't uninvent the wheel. It's going to be very difficult to persuade people not to use them" ( $2 \mathrm{G}$, Committed)

The discourses on climate change and flying illustrate the conflict that can emerge for individuals who lead pro-environmental lifestyles within the home context, but wish to continue to fly, a behaviour that many recognise as being problematic. However, the discussion of holidays in general revealed that not only was the issue of flying related to the contested notion of climate change, but the very sites of practice in which holidays were based challenged the logic of 'sustainable lifestyles'; in short, holidays were 'off limits' to sustainability:

"I suppose people think a holiday is a holiday and that they go there to relax and do their own thing. And you know, it sounds a bit nasty but you know, when you're holiday, you're really thinking about yourself aren't you because it's your time away". (3C, Mainstream)

"So long as you turn the lights off at home for a couple of weeks eh?!" (3F, Mainstream) 
These sentiments illustrate the importance of looking beyond the immediate issue of climate change and focusing on the significance of the sites of practice in which individuals perform certain symbolically important practices (Shove, 2003). In this case, not only does climate change represent a contested topic amongst many committed environmentalists, but it also conflicts with existing and pre-determined notions of consumption in leisure and tourism contexts. Moreover, this conflict is recognised as a problem, an issue for which there appears to be no easy solution:

"I'm concerned about the sheer volume of air traffic but at the same time, I sometimes like to go on an aeroplane, which is a paradox isn't it?" (2A, Committed)

\section{THE SUSTAINABLE LIFESTYLE: A USEFUL CONCEPT?}

In this final section, we discuss our findings in relation to two key elements of the market-orientated 'sustainable lifestyles' approach that need to be addressed if both intellectual and pragmatic agendas for behaviour change are to be advanced beyond the 'marginal' changes many now see as unsustainable (Johnson, 2008; Crompton and Thogersen, 2009). First, we explore the links between 'sustainable lifestyles' concepts and attitudes to climate change. Second, we examine the potential for market-orientated concepts for promoting sustainable lifestyles through social marketing techniques.

Throughout these discussions, the rapidly shifting topography of climate change debates and their relationship with the science and policy of dealing with environmental change should be noted, particularly the potential of high profile events like the Copenhagen Climate Summit to frame public discourses. To this 
extent, the data presented in this paper represent a temporally mediated empirical contribution to the debates on the public understanding of climate change and the ways in which individuals respond to such issues. Although the data are therefore limited in this way, the arguments we pursue below have resonance in the context of contemporary climate change discourses, which are changing on a regular basis and do not remain static for even months at a time (BBC, 2010). Indeed, subsequent research by the authors, undertaken in similar contexts but at later dates (Barr and Prillwitz, in press; Barr et al., 2010) demonstrates the relevance of the arguments pursued in this paper.

\section{1 'Sustainable lifestyles' and attitudes to Climate Change}

The dominance of neo-liberal approaches to encouraging pro-environmental behaviours rests on an irresistible fusion between collective responsibility and a desire for consumer goods and services. Throughout a liberalising Western World, shrinking states have placed a greater burden of responsibility on individuals to both consume for the sake of the market and also to take responsibility for issues conventionally ascribed to the state (Clarke et al., 2007). Whatever perspective is adopted in this process, the means of creating responsible citizen-consumers is based on their ability to consume, albeit less voraciously than at present.

Accordingly, our first proposition is that within the stable, routinised, everyday context of the household, citizens can be effective agents for change, embedding sustainability in the everyday habits and practices that comprise the basis of normality (Spaargaren, 2004; Shove, 2003; Shove et al., 2007). However, we contend that this largely comfortable coalition between citizen and 
consumer simply does not function when more conspicuous forms of consumption are considered in spaces that are imbued with the symbolism of the extra-ordinary (Urry, 2002). As such, it is possible for 'citizen-consumers' (Clarke et al., 2007) to flourish in sites of practice where consumption is not challenged; yet holidays, where individuals are at the place of their dreams (Shaw and Williams 2004) may constitute different and 'out of bounds' forms of important symbolic consumption. Evidence from research by the authors and scholars from tourism studies (e.g. Barr et al., 2010; Dickinson and Dickinson, 2006) suggests that touristic spaces hold alternative meanings for consumption that make the transference or 'spill-over' of pro-environmental practices from daily contexts more problematic, potentially leading to an inversion in behaviours between the home and the holiday (Krippendorf, 1987) Indeed, it is in the holiday context where individuals have to confront the issue of climate change, with which it is possible to consciously separate from the local concerns of environmental protection in and around the home. Accordingly, sites of leisure and tourism not only represent important areas of consumption but also challenge the citizen-consumer to confront the simple yet significant consequences of their impacts on climate change.

In this scenario, sites of practice may become a major framing device for understanding the conflict that many individuals feel between the settled adaptation of lifestyles in the home to deal with the everyday issues of waste, energy and water, and the challenges to symbolically important consumption that climate change poses when in leisure and tourism contexts. The research in this paper suggests that flying is illustrative of such symbolically valuable consumption, seen within a wider framework of touristic experiences. This is 
inevitably entwined with the ways in which climate change also poses a challenge to different scales of consumption, which present certain forms of practice (like flying) as being more problematic to reduce than apparently simpler, 'small' actions (such as recycling materials). Yet questions of scale are equally entwined with the symbolic value of consumption in any particular context, which may mean that adopting the same practice at different sites is a question of symbolic and representational importance. Therefore, to ignore sites of practice is to neglect a key challenge to the citizen-consumer concept, one that is set within a new and volatile age of climate politics.

\subsection{Marketing Reduced Consumption?}

In the UK, national policy for behaviour change is predicated on adopting social marketing approaches to promote a wide range of behavioural changes, from reduced short-haul flights to recycling (DEFRA, 2008). Indeed, the use of segmentation is viewed as critical for the successful implementation of strategic behavioural goals.

The research reported in this paper demonstrates that constructing segments can be highly problematic and this was especially the case with individuals who were very committed to the environment in and around the home and yet were both equivocal on the issue of climate change and also demonstrated an unwillingness to reduce certain carbon intensive behaviours, such as flying. This situation emphasises the importance of locating different sites of practice and the symbolic importance of these for different forms of consumption for different groups. For example, the statistical analyses of the sample on which the focus groups were based indicates that individuals who 
were the most committed to environmental issues tended to be wealthier (Barr and Gilg, 2006), a socio-economic finding corroborated by recent research from CACI (2008). However, such individuals are much more likely to use their disposable income to take frequent holidays using air travel.

However, there is no doubt that the notion of 'sustainable lifestyles' is highly problematic and is rendered almost redundant when explored across sites of practice that represent different consumption contexts. The second proposition we wish to make therefore is that the valuable research on social practices, which has largely been focused on the home environment (Spaargaren, 2004; Shove, 2003; Gregson et al., 2007) needs to be extended to the leisure and tourism context (Verbeek and Mommass, 2008). Social marketers need to appreciate the important values, norms and routines that govern the choices individuals as tourists make about their holidays and crucially how these differ from the home context.

This does not imply that segmentation is invalid, but it does require recognition that holidays are specific sites of practice where individuals encounter issues such as climate change in different ways. As Peattie and Peattie (2009) have noted, social marketing still needs to find and adopt strategies that engage with high-consumption activities such as flying; as such it is the holiday, rather than the home, that poses the most significant challenge (and opportunity) to the sub-discipline of social marketing.

\section{CONCLUSION}

Since the onset of enquiries into environmental consciousness, the issue of 'context' has been a crucial framing device in understanding the ways in which 
individuals interpret and act towards the environment (Owens, 2000). However, context has often referred to individual circumstance - an exploration of how individuals have formed their identities and practices. In this paper, we have attempted to emphasise the importance of the social and spatial context through the sites of practice in which individuals perform. These sites of practice not only frame different trajectories of behaviour, as one might expect, but they also expose individuals to the unsettling contradictions and conflicts that emergent issues like climate change reveal. To this extent, the citizen stands at a fork in road; there is the opportunity to face up to the challenge of climate change within contexts of consumption and to explore the ways in which social marketing strategies can be adapted to deal with issues such as flying and other carbon intensive activities. There is also the option to continue along the existing path, focusing on the home context, which provides simple and palatable solutions to citizens as consumers.

Sceptics of this progressive and consumption-oriented perspective (e.g. Crompton and Thogersen, 2009) do not accept this approach will work; they call for urgent action. Our argument is that this call is premature, given the lack of attention paid to alternative sites of practice until now. Rather, we advocate an intellectual and practical study of how social marketing can be used to plot and promote behaviour change between contexts through renewed engagements with consumers and markets (Lusch and Vargo, 2007).

There then emerges the question of 'will this be enough?' This is not a question we as social scientists can answer; the one statement we can make with confidence, however, is that the state of knowledge, collective denials and unwillingness to ascribe individual responsibility for climate change that we 
have demonstrated here and which pervade the literature mean that more radical measures aimed at fiscal or regulatory reform are likely to fail; however unpalatable working with consumption may be, there is no indication that it has lost its appeal within a dominant neo-liberal system of globalisation.

\section{Acknowledgement}

The authors would like to thank the UK Department for the Environment, Food and Rural Affairs (DEFRA) for their financial support to undertake the research report in this paper (Project No. EPES040514). 


\section{References}

Anable, J., 2005. 'Complacent Car Addicts' or 'Aspiring Environmentalists'? Identifying travel behaviour segments using attitude theory. Transport Policy $12,65-78$

Anable, J., Lane, B., Kelay, T., 2006. A Review of Public Attitudes to Climate Change and Transport Behaviour. Department for Transport [Online], London. Available at:

http://www.dft.gov.uk/pgr/sustainable/climatechange/areviewofpublicattitudesto cl5730. Accessed 29th July 2010.

Andreasen, A. R., 2006. Social Marketing in the $21^{\text {st }}$ Century. Sage, London.

Barr, S., 2008. Environment and Society: sustainability, policy and the citizen. Ashgate, Aldershot.

Barr, S. and Gilg, A. W. 2006. Sustainable Lifestyles: framing environmental action in and around the home. Geoforum 37, 906-920.

Barr, S., Gilg, A., Shaw, G., 2006. Promoting Sustainable Lifestyles: a social marketing approach. DEFRA [Online], London. Available at http://www.sustainabledevelopment.gov.uk/publications/pdf/desk-research2.pdf. Accessed $29^{\text {th }}$ July 2010.

Barr, S. and Prillwitz, J., in press. Sustainable Travel: citizens - mobilities policy in Newton, P. (Ed.) Landscapes of Urban Consumption. CSIRO / Techne, Amsterdam..

Barr, S., Shaw, G., Coles, T. E. and Prillwitz, J., 2010. 'A holiday is a holiday': practicing sustainability home and away. Journal of Transport Geography 18, $474-481$ 
BBC, 2010. BBC Climate Change Poll - February 2010. Available from: http://news.bbc.co.uk/nol/shared/bsp/hi/pdfs/05_02_10climatechange.pdf. Accessed 19th February 2010.

Becken, S., 2007. Tourists' Perception of International Air Travel's Impact on the Global Climate and Potential Climate Change Policies, Journal of Sustainable Tourism 15, 351-368.

Becken S. and Hay, J. E., 2007. Tourism and Climate Change: risks and opportunities. Channel View, Clevedon.

CACI, 2008. Green Acorn Classification System. CACI, London.

Cabinet Office, 2010. Building the Big Society, Cabinet Office Press Release

[Online]. Cabinet Office, London. Available from: http://www.cabinetoffice.gov.uk/media/407789/building-big-society.pdf._Accessed 29th July 2010

Chapman, L., 2007. Tourism and climate change: a review. Journal of Transport Geography 15, 354-367.

Clarke, J., Newman, J., Smith, N., Vidler, E., Westmarland, L., 2007. Creating Citizen-Consumers; Changing Publics and Changing Public Services. Sage, London.

Connelly, J. and Smith, G., 2003. Politics and the Environment. $2^{\text {nd }}$ edition. Routledge, London.

Crompton, T. and Thogersen, J., 2009. Simple and Painless? The limitations of spillover in environmental campaigning. WWF UK, London.

Dallen, J., 2007. Sustainable transport, market segmentation and tourism: the Looe Valley branch line railway, Cornwall, UK. Journal of Sustainable Tourism $15,180-199$. 
Darnton, A. and Sharp, V., 2006. Segmenting for Sustainability. Social Marketing Practice, Didcot.

Department of the Environment, Food and Rural Affairs (DEFRA), 2008. Framework for Environmental Behaviours. DEFRA, London.

Department of the Environment, Food and Rural Affairs (DEFRA), 2005. Securing the Future. DEFRA, London.

Dickinson. J.E. and Dickinson, J. A., 2006. Local Transport and Social Representations: Challenging the Assumptions for Sustainable Tourism. Journal of Sustainable Tourism 14, 192-208.

Frame, B. and Newton, B., 2007. Promoting sustainability through social marketing: examples from New Zealand, International Journal of Consumer Studies 31, 571-581.

French, J. Blair-Stevens, C., McVey, D. and Merritt, R. (eds.), 2009. Social Marketing and Public Health: theory and practice. OUP, Oxford.

Gossling, S. and Peeters, P., 2007. 'It Does Not Harm the Environment!' An Analysis of Industry Discourses on Tourism, Air Travel and the Environment, Journal of Sustainable Tourism 15, 402-417.

Graham, B. and Shaw, J., 2008. Low-cost airlines in Europe: Reconciling liberalization and sustainability, Geoforum 39, 1439-1451.

Gregson, N., Metcalfe, A. and Crewe, L, 2007. Identity, mobility and the throwaway society. Environment and Planning D: Society and Space 25, 682700.

Hunter, C. and Shaw, J., 2007. The ecological footprint as a key indicator of sustainable tourism. Tourism Management 28 (1), 46-57. 
Jackson, T., 2005. Motivating Sustainable Consumption: a review of evidence on consumer behaviour and behavioural change. Sustainable Development Research Network, London.

Johnson, J., 2008. The citizen-consumer hybrid: ideological tensions and the case of Whole Foods Market, Theory and Society 37, 229-270.

Krippendorf, J., 1987. The Holiday Makers: Understanding the Impact of Leisure and Travel. Butterworth-Heinemann, Oxford.

Leiserowitz, A. A., 2005. American risk perceptions: is climate change dangerous? Risk Analysis, 25 1433-1456.

Lorenzoni, I. and Pidgeon, N., 2006. Public views on climate change: European and USA perspectives, Climatic Change 77 (1-2), 73-95.

Lorenzoni, I., Nicholson-Cole, S. and Whitmarsh, L., 2007. Barriers perceived to engaging with climate change among the UK and their policy implications, Global Environmental Change 17, 445-459.

Lusch, R. and Vargo, S. eds., 2007. The Service-Dominant Logic of Marketing. ME Sharpe, New York.

McKenzie-Mohr, D., 2000. New Ways to Promote Proenvironmental Behavior: Promoting Sustainable Behavior: An Introduction to Community-Based Social Marketing, Journal of Social Issues 56, 543-554.

McKenzie-Mohr, D. and Smith, W., 1999. Fostering Sustainable Behaviour: an introduction to community based social marketing. New Society Publishing, New York.

Moffatt, I., 1996. Sustainable Development: principles, analysis and policies. Parthenon, London. 
National Statistics, 2010. Regional Trends. Available from: http://www.statistics.gov.uk/regionaltrends. Accessed 12th October 2010.

Owens, S., 2000. Engaging the public: information and deliberation in environmental policy, Environment and Planning A 32, 1141-1148.

Peattie, K. and Crane, A., 2005. Green marketing: legend, myth, farce or prophesy? Qualitative Market Research 8,357-370.

Peattie, K. and Peattie, S., 2009. Social marketing: a pathway to consumption reduction? Journal of Business Research 62, 260-268.

Prime Minister's Office, 2010. Big Society Speech. Prime Minister's Office. Prime Ministers' Office [online], London. Available from: http://www.number10.gov.uk/news/speeches-and-transcripts/2010/07/bigsociety-speech-53572. Accessed 29th July 2010.

Ryley, T. and Davison, L., 2008. UK air travel preferences: Evidence from an East Midlands household survey, Journal of Air Transport Management 14, 4346.

Scammell, M., 2000. The Internet and Civic Engagement: the age of the citizenconsumer, Political Communication 17, 351-355.

Shaw, G. and Williams, A. M., 2004. Tourism and Tourism Spaces. Sage, London.

Shove, E., 2003. Comfort, Cleanliness and Convenience: the social organization of normality. Berg, Oxford.

Shove, E. Watson, M., Hand, M. and Ingram, J., 2007. The Design of Everyday Life. Berg, Oxford.

Spaargaren, G., 2004. Sustainable Consumption: a theoretical and environmental policy perspective. In Southerton, D., Chappells, H. andVan 
Vilet, B. (Eds.) Sustainable Consumption: the implications of changing infrastructures of provision. Edward Elgar, Cheltenham, pp. 15-31.

Spaargaren, G. and Mol, A. P. J., 2008. Greening global consumption: Redefining politics and authority, Global Environmental Change 18, 350-359.

Stern, N. H., 2006. The Economics of Climate Change. HM Treasury, London.

Stoll-Kleemann, S., O’Riordan, T., Jaeger, C.C., 2001. The psychology of denial concerning climate mitigation measures: evidence from Swiss focus groups, Global Environmental Change 11, 107-117.

Urry, J., 2002. The Tourist Gaze. Sage, London.

Whitmarsh, L., 2009. What's in a name? Commonalities and differences in public understanding of "climate change" and "global warming". Public $\begin{array}{llll}\text { Understanding } & \text { of } & \text { Science } & 18,\end{array}$ 


\section{Appendix 1}

\section{Characteristics of Participants in the Focus Groups}

\begin{tabular}{|c|c|c|c|c|c|c|}
\hline $\begin{array}{c}\text { Group } \\
\text { ('Environmentalist') }\end{array}$ & Respondent & Gender & Occupation & Marital Status & Children & Age \\
\hline \multirow[t]{8}{*}{1 Committed } & A & Female & Artist & Married & $3=13,15,17$ & 38 \\
\hline & $\mathrm{B}$ & Female & Organic Farmer & Single & 0 & 54 \\
\hline & $\mathrm{C}$ & Female & Housewife & Married & $2=13,14$ & 45 \\
\hline & $\mathrm{D}$ & Female & $\begin{array}{l}\text { Local Government } \\
\text { Worker }\end{array}$ & Single & $1=4$ & 32 \\
\hline & $\mathrm{E}$ & Male & Shop Owner & Cohabiting & $2=10,14$ & 43 \\
\hline & $\mathrm{F}$ & Female & Accounts Officer & Divorced & $1=8$ & 37 \\
\hline & $\mathrm{G}$ & Male & Retired & Married & $2=$ no ages given & 69 \\
\hline & $\mathrm{H}$ & Female & Sales person & Married & $1=37$ & 62 \\
\hline \multirow[t]{7}{*}{2 Committed } & $\mathrm{A}$ & Male & Engineer & Married & $?$ & 63 \\
\hline & $\mathrm{B}$ & Female & Customer relations & Divorced & $2=22,21$. & 51 \\
\hline & $\mathrm{C}$ & Female & Unemployed & Single & 0 & 20 \\
\hline & $\mathrm{D}$ & Female & Care Worker & Divorced & 0 & 40 \\
\hline & $\mathrm{E}$ & \begin{tabular}{|l|} 
Female \\
\end{tabular} & Semi-Retired & Married & 0 & 65 \\
\hline & $\mathrm{F}$ & Female & Retired & Married & $2=32,30$ & 72 \\
\hline & $\mathrm{G}$ & Female & Nurse & Married & $2=22,25$. & 52 \\
\hline \multirow[t]{5}{*}{3 Mainstream } & $\mathrm{A}$ & Female & Shop Assistant & Married & $4=36,34,32,30$ & 55 \\
\hline & $\mathrm{B}$ & Male & Engineer & Cohabiting & 0 & 22 \\
\hline & $\mathrm{C}$ & Female & Insurance Consultant & Single & 0 & 20 \\
\hline & $\mathrm{D}$ & \begin{tabular}{|l|} 
Male \\
\end{tabular} & Office Manager & Married & $2=25,23$. & 55 \\
\hline & $\mathrm{E}$ & Female & Retired & Married & $1=35$ & 63 \\
\hline
\end{tabular}




\begin{tabular}{|c|c|c|c|c|c|c|}
\hline & $\mathrm{F}$ & Male & Electrician & Cohabiting & $4=25,22,20,18$ & 57 \\
\hline \multirow{6}{*}{4 Mainstream } & $\mathrm{A}$ & Female & Nurse & Cohabiting & 0 & 35 \\
\hline & $\mathrm{B}$ & Female & Operations Manager & Married & $1=15$ months & 30 \\
\hline & $\mathrm{C}$ & Male & $\begin{array}{l}\text { Local Government } \\
\text { Officer }\end{array}$ & Single & 0 & 33 \\
\hline & $\mathrm{D}$ & Male & Postman & Single & 0 & 47 \\
\hline & $E$ & Male & Engineer (Health) & Cohabiting & 0 & 26 \\
\hline & $\mathrm{F}$ & Male & Estate Agent & Separated & 0 & 30 \\
\hline \multirow[t]{6}{*}{5 Occasional } & $\mathrm{A}$ & Female & Shop Assistant & Married & $1=25$ & 55 \\
\hline & $\mathrm{B}$ & Female & Voluntary Worker & Married & $4=29,32,34,38$ & 59 \\
\hline & $\mathrm{C}$ & Male & Science Student & Single & 0 & 25 \\
\hline & $\mathrm{D}$ & Female & Nurse & Single & 0 & 27 \\
\hline & $\mathrm{E}$ & Female & $\begin{array}{l}\text { Call centre } \\
\text { worker/student }\end{array}$ & Married & $1=2$ & 24 \\
\hline & $\mathrm{F}$ & Male & Chef & Married & 0 & 26 \\
\hline \multirow[t]{6}{*}{6 Occasional } & $\mathrm{A}$ & Female & Shop Assistant & Married & $1=30$ & 60 \\
\hline & $\mathrm{B}$ & Male & Trainee Doctor & Single & 0 & 23 \\
\hline & $\mathrm{C}$ & Male & Mechanic & Single & 0 & 24 \\
\hline & $\mathrm{D}$ & Female & Receptionist & Single & 0 & 35 \\
\hline & $E$ & Female & Housewife & Divorced & $2=24,22$ & 48 \\
\hline & $\mathrm{F}$ & Female & Dental Assistant & Cohabiting & 0 & 20 \\
\hline \multirow[t]{5}{*}{7 Non } & $\mathrm{A}$ & Female & Visual Merchandiser & Single & 0 & 22 \\
\hline & $\mathrm{B}$ & Male & Warehouse Worker & Married & $1=4$ & 26 \\
\hline & $\mathrm{C}$ & Male & Student & Single & 0 & 23 \\
\hline & $\mathrm{D}$ & Female & Waitress & Cohabiting & 0 & 27 \\
\hline & $\mathrm{E}$ & Female & Housewife & Divorced & $2=24,22$ & 48 \\
\hline
\end{tabular}




\begin{tabular}{|c|c|c|c|c|c|c|}
\hline & $\mathrm{F}$ & Male & Hotel Worker & Single & $1=7$ & 30 \\
\hline & $\mathrm{G}$ & Male & Trainee Teacher & Single & 0 & 27 \\
\hline \multirow[t]{11}{*}{8 Non } & $\mathrm{A}$ & Male & Postgraduate Student & Married & 0 & 31 \\
\hline & $\mathrm{B}$ & Female & Call centre worker & Single & 0 & 24 \\
\hline & $\mathrm{C}$ & Female & Hospitality Manager & Single & 0 & 28 \\
\hline & $\mathrm{D}$ & Female & Psychologist & Cohabiting & $2=3,5$ & 31 \\
\hline & $\mathrm{E}$ & Female & $\begin{array}{l}\text { American Visa - Full } \\
\text { Time Barmaid }\end{array}$ & Single & 0 & 20 \\
\hline & $\mathrm{F}$ & Female & Fitness Instructor & Single & 0 & 22 \\
\hline & $\mathrm{G}$ & Male & Bricklayer & Cohabiting & $1=4$ & 25 \\
\hline & $\mathrm{H}$ & Male & Mechanic & Married & $2=1,3$ & 27 \\
\hline & $\mathrm{I}$ & Male & Chef & Single & 0 & 29 \\
\hline & $\mathrm{J}$ & Female & Legal Assistant & Single & 0 & 27 \\
\hline & $\mathrm{K}$ & Male & Student & Married & $1=1$ & 29 \\
\hline
\end{tabular}

